\title{
O partido republicano norte-americano em 1960 e 201 2: uma ascensão conservadora?
}

\section{Camila Feix Vidal}

\section{Resumo}

Este estudo tem como propósito analisar a suposta radicalização conservadora do Partido Republicano norte-americano por meio de estudo e comparação de suas plataformas nacionais no período de 1960 e 20 I2.Assim, seu objetivo é duplo: analisar mudanças e continuidades com relação ao posicionamento do Partido Republicano com base nas suas plataformas nacionais e, como consequência do método escolhido, contribuir para o uso de novas técnicas de abordagem no estudo de ideologia partidária. Os resultados mostraram que há certa continuidade ideológica, no entanto, há importantes rupturas no que diz respeito à linguagem, às ênfases e à própria agenda partidária defendida, implicando posicionamentos políticos em 2012 completamente distintos em relação a certas questões e categorias em 1960.

Palavras-chave: ideologia; conservadorismo; partido republicano; Estados Unidos; plataformas.

\begin{abstract}
This paper intents to analyze the Republican Party's supposedly conservative ascendancy through a comprehensive study and comparison of its 1960 and 2012 national platforms. Therefore, this work presents two main goals: to analyze changes and continuities with regards to the Republican Party's political positioning based on its national platforms and, as a consequence of the process chosen, to contribute to the use of new techniques in the study of party's ideology. The results indicate some ideological continuities; nevertheless, there are important changes as far as the speech, the emphasis and the political positioning in 2012, which show, overall, a very different pattern compared with the one of 1960.
\end{abstract}

Keywords: ideology; conservatism; Republican Party; United States; platforms.

Artigo recebido em 25 de março de 20I5; aceito para publicação em 6 de julho de 2015.

\section{Sobre a autora}

Graduada em Relações Internacionais pela Florida International University (FIU) e Universidade Federal do Rio Grande do Sul (UFRGS); mestrado e doutorado (em andamento) em Ciência Política pela Universidade Federal do Rio Grande do Sul (UFRGS). E-mail: camilafeixvidal@gmail.com 


\section{Introdução'}

A literatura norte-americana recente vem produzindo trabalhos sobre uma suposta polarização partidária, atribuindo ao Partido Democrata uma ideologia crescentemente liberal ${ }^{2}$ e ao Partido Republicano, ao contrário, uma ideologia amplamente conservado$\mathrm{ra}^{3}$. O Partido Republicano, no entanto, passou a ser o foco principal desses estudos já que lhe é atribuído um deslocamento mais acentuado para o extremo do espectro político direita $v s$. esquerda, no caso, em direção à extrema direita, ou radical right, (Pierson e Hacker, 2005) por conta da defesa de políticas consideradas ultraconservadoras. $\mathrm{O}$ movimento conservador norte-americano e o Partido Republicano não são, entretanto, termos intercambiáveis. Até a década de 1960 esse partido não era reconhecido pela defesa de políticas conservadoras, ao contrário, o GOP ${ }^{4}$ era considerado um partido progressista que valorizava o papel do governo federal na condução da política norte-americana. Urbano e atrelado ao norte do país, ele seria o responsável pelo fim da escravidão e defesa do movimento de emancipação racial. A partir de 1964, no entanto, com a candidatura de Barry Goldwater à presidência nacional e, em especial, na eleição à presidência de Ronald Reagan em 1980, o conservadorismo passaria a ser característica intrínseca do Partido Republicano. Assim, desde a década de 1980, a literatura que versa sobre esse tema reflete a hipótese de que há uma polarização

1. A versão preliminar deste trabalho foi apresentada no IX Encontro da ABCP Brasília, 4-7 de agosto de 2014. Agradeço as sugestões e os comentários feitos pelo coordenador e debatedor da área temática, prof. Renato Perissinotto.

2. O termo "liberal" no contexto norte-americano possui uma especificação própria. Refere-se à defesa de uma maior ingerência do governo na imposição de políticas de bem-estar social na esfera econômica e, ao contrário, o distanciamento do governo nas questões sociais e de ordem "privada". O liberalismo, assim, posiciona-se de maneira oposta ao "conservadorismo" (tal como no contexto norte-americano) que defende uma menor atuação do Estado na área econômica e uma maior ingerência na área social "privada".

3. Pierson e Hacker (2005); Stonecash (2010); Mann e Ornstein (2012); Levendusky (2009); Brewer e Stonecash (2009); Mccarty, Poole e Rosenthal (2006); Fiorina (1999, 2005); Fiorina e Abrams (2008); Sinclair (2006); Layman (2001); Black e Black (2007) entre outros.

4. Grand Old Party (GOP) é utilizado como sinônimo de Partido Republicano. 
partidária atualmente nos Estados Unidos que tem como principal expoente uma ascensão conservadora perpetuada pelo Partido Republicano.

O estudo proposto se insere nessa mesma área de estudos na Ciência Política, especialmente aqueles sobre ideologia partidária ${ }^{5}$; no entanto, busca analisar essa suposta polarização partidária e radicalização conservadora do Partido Republicano por meio de uma metodologia diferenciada. Entende-se que a melhor maneira de identificar a ideologia de um partido seja mediante suas plataformas nacionais ${ }^{6}$. Em se tratando de um fenômeno nacional (a suposta polarização partidária e radicalização conservadora do GOP), o uso de plataformas nacionais passa a ser considerado o mais apropriado. Realizadas a cada quatro anos, elas são o único documento oficial do partido (endossado por todos, tácita ou formalmente) e, portanto, podem ser consideradas o "retrato" dele no momento em que foram compostas - refletem tanto suas ideologias, de maneira mais abstrata; como as posições políticas defendidas, de maneira mais factual. Nesse estudo, optou-se por analisar a plataforma mais recente do partido (2012) e a plataforma anterior à candidatura de Goldwater (1960). Se, de fato, a candidatura deste e a plataforma por ele apresentada marcam o início da ascensão do conservadorismo no Partido Republicano e, consequentemente o início da radicalização conservadora republicana, torna-se importante analisar o período anterior a essa ascensão e, supostamente, de moderação em comparação com o atual período.

A análise de programas partidários está inserida em uma metodologia mais ampla de análise de conteúdo, no entanto, vem sendo progressivamente estruturada de maneira a abarcar diferentes métodos no estudo específico de textos partidários. Na maioria dos casos, a análise de plataforma é feita de maneira comparada, buscando correlações, ou a falta delas, com outras plataformas. O trabalho proposto visa utilizar dessas técnicas para a análise das plataformas nacionais republicanas, buscando comparar as plataformas de 1960

5. A “ideologia" é entendida aqui de maneira inclusiva, definida como um corpo normativo sobre a natureza do homem e da sociedade, bem como sua organização e propósito (Seliger, 1976).

6. Plataformas, uso nos Estados Unidos, e manifestos, uso no Reino Unido, referem-se aos programas partidários, expostos oficialmente pelo partido para uma eleição. 
e de 2012, atentando para sua linguagem, ênfases e estrutura, bem como para o posicionamento do partido referente a determinadas categorias que o caracterizam no dado momento e que poderiam indicar presença, ou ausência, de princípios conservadores. O objetivo desse trabalho é, portanto, duplo: analisar mudanças e continuidades com relação ao posicionamento do Partido Republicano com base nas suas plataformas nacionais e, como consequência do método escolhido, contribuir para o uso de novas técnicas de abordagem na análise de conteúdo, construídas especificamente para esse fim.

Os resultados mostraram que há certa continuidade na posição do partido em determinados temas, no entanto há importantes rupturas no que diz respeito a linguagem, estrutura, ênfases e no próprio posicionamento partidário, implicando posições políticas distintas nos dois períodos analisados. De forma geral, as plataformas estudadas apresentam como documentos bastante diferentes, por vezes com ideologias inversas, o que contribui para o argumento de mudança ideológica pela qual o Partido Republicano passou a partir da segunda metade do século XX.

\section{Análise de programas partidários}

O estudo de programas partidários não faz parte do mainstream na Ciência Política, nem mesmo na área de partidos políticos. Ainda assim, é o único documento oficial do partido em que seus posicionamentos, objetivos, avaliações e mesmo ideologias em um dado momento estão expostos ${ }^{7}$. Segundo Budge et al. (2001, 51), "if one wants to study party policy, and not the policies advocated by internal factions or individuals inside the party, one has to study the party manifesto”. Já para Laver e Garry (2000, 619), programas partidários "represent a core source of information about the policy positions of political actors”. Pomper $(1967,319)$ vai mais além: “a national party's policy commitments are found in its platform. Adopted by its only meaningful organ, the nominating convention, and presented to the voters as the Presidential election approaches, it

7. Entende-se que os documentos e pronunciamentos de líderes partidários e candidatos não refletem a posição do partido, ao menos oficialmente. As plataformas nacionais, nesse sentido, são os únicos documentos endossados por todos no partido - tácita ou formalmente. 
most fully represent the party's intentions". Por fim, para Robertson (1976 apud Budge; Robertson e Hearl, 1987), "they are the only direct and clear statements of party policy available to the electorate and directly attributable to the party as such". Este estudo parte deste pressuposto de que os programas partidários são o mais importante e sólido documento que um partido político produz em relação aos seus posicionamentos políticos e visões normativas de mundo. Um programa partidário significa, portanto, o retrato ideológico do partido em um dado momento.

A análise de programas partidários não é uma abordagem nova nos estudos de partidos e ideologias partidárias. Gerald Pomper, por exemplo, já atentava, na década de 1960, para a importância de estudos aprofundados com base nesses documentos e as várias possibilidades de se compreender as mudanças intra e interpartidárias a partir deles (Pomper, 1967). No entanto, apesar de relativamente antiga, ainda pode ser considerada marginal no âmbito da Ciência Política, em especial e paradoxalmente nos Estados Unidos em comparação com estudos europeus. Os estudos de plataformas ali desenvolvidos tendem a ser esporádicos e bastante factuais. Em sua maioria seguem uma abordagem candidate centered e racionalista, como é o caso dos estudos de Pomper (1967), Fishel (1985) e Maisel (1993-1994).

No âmbito norte-americano, esses estudos podem ser resumidos em dois tipos: aqueles que versam sobre a construção de determinadas plataformas, no sentido de como são produzidas pelos líderes partidários (Weinberg, 1977-1978; Maisel, 1993-1994) e aqueles que a analisam a partir de uma metodologia típica de análise de conteúdo, em sua maioria buscando verificar a frequência de frases, parágrafos ou argumentos e a sua posterior categorização, seja para verificar uma relação com a opinião pública (Monroe, 1983; Ginsberg, 1976), seja para relacionar promessas com políticas postas em prática pelos eleitos (Pomper, 1967; Fishel, 1985). Na maioria desses trabalhos, as plataformas são codificadas manualmente em um processo de handcoding, atentando para determinadas frases ou argumentos, ou ainda computadas em termos de ênfases a determinados temas e palavras, quantas vezes o partido $\mathrm{X}$ mencionou a economia na sua plataforma em relação ao partido Y, por exemplo, e pledges, quantas promessas o partido $\mathrm{X}$ fez em relação à política externa em comparação com a educação, por exemplo. 
A análise de programas partidários, atualmente, parece ser mais estudada e divulgada no âmbito europeu, onde teve início o Comparative Manifesto Project (CMP) desenvolvido por Michael Laver e Ian Budge entre outros, que visa posicionar os programas partidários de diversos países em uma escala direita $v s$. esquerda por meio de técnicas de handcoding. A codificação manual utilizada pelo CMP é feita de maneira sistemática a partir de um único padrão de códigos. Assim, toda a plataforma é manualmente dividida em quasi-sentences que serão posteriormente categorizadas de acordo com um determinado tema ( 7 temas subdivididos em 56 subtemas) e a menção feita a ele (se positivo ou negativo). É importante mencionar que o CMP expõe a chamada "saliency theory", que assume que os partidos competem entre si e se caracterizam pela ênfase dada em diferentes pontos, ou seja, nas diferentes prioridades que expõem em seus programas políticos (Laver e Budge, 1992). Assim, um partido enfatizaria determinados temas em detrimento de outros e sua caracterização se daria, segundo essa abordagem, justamente nesses temas prioritários.

Ainda que a codificação manual continue tendo espaço nas análises de conteúdo no que diz respeito aos programas partidários, sendo o CMP a maior prova, outros métodos vêm sendo disponibilizados com esse mesmo fim, entre eles determinados programas computacionais, tais como os desenvolvidos por Laver, Benoit e Garry (2003) e por Slapin e Proksch (2008). Em ambos os casos, utiliza-se de determinadas técnicas que contabilizam e codificam palavras, frases, parágrafos e argumentos com o objetivo de posicionar o programa partidário no espectro político direita $v s$. esquerda. Assim, alguns temas e a menção feita a eles (se positiva ou negativa) são pré-definidos como de "esquerda" ou de "direita" e, dependendo da frequência e categorização dos dados escolhidos na plataforma, o partido passa a ser situado em uma parte desse espectro político.

É necessário fazer uma breve digressão sobre o estado da arte atualmente no que diz respeito a esses estudos. Em primeiro lugar, há duas concepções distintas nos trabalhos sobre ideologia partidária que se utilizam de plataformas: uma que privilegia o "exterior" e a outra que privilegia o "interior" do texto. A primeira vertente está preocupada com a "forma" da plataforma, ou seja, a "embalagem” em que ela esta envolta, trabalhando, assim, com a estrutura formal, no sentido de como o texto está construído em questão de 
parágrafos, páginas e palavras, por meio de uma metodologia preferencialmente quantitativa. A segunda vertente está preocupada com o "conteúdo", com a "substância" da plataforma, privilegiando, dessa maneira, uma dimensão mais qualitativa por meio da leitura e interpretação do texto. Para Budge et al. (2001), essa separação não é só metodológica, mas também se refere a diferentes abordagens teóricas: enquanto a primeira privilegia a abordagem da "saliência", a segunda privilegiaria a do "confronto".

A "saliency theory" (Budge; Robertson e Hearl, 1987; Budge et al., 2001; Laver, 2001) diz respeito ao entendimento de que os partidos competem entre si através da prioridade (ênfases) de determinados temas. Ao invés de tomar posicionamentos específicos e diferentes entre si, os partidos enfatizariam diferentes assuntos, convergeriam no posicionamento da maioria dos temas, posicionando-se de maneira central e se opondo a confrontos diretos com outros partidos: "mostly, ideas about what to do on each issue are shared (cut taxes, extend welfare, etc.), what differs is the degree to which taxes or welfare are mentioned by the different documents. [...] Election programmes therefore try to promote a party's proprietary issues and polarities and downgrade other issues and priorities" (Budge et al., 2001, 7-8). O argumento é simples: o objetivo do programa partidário é angariar votos, sendo a repetição o seu maior trunfo: "making policy points involves highliting them, repeating them in slightly varied form and coming back to them in a variety of contexts" (Budge et al., 2001). Nesse sentido, a frequência das palavras indicaria a ênfase em determinados temas e, por conseguinte, as prioridades do partido e sua caracterização ideológica a partir disso. Ou seja, entende-se que as palavras em uma plataforma são dados e, mais que isso, escolhas, que demonstram certas prioridades, que, por sua vez, tendem a refletir uma visão de mundo e ideologia do partido naquele dado momento. Os programas e softwares computacionais, nessa abordagem, são as opções mais utilizadas. Por outro lado, o "confrontational approach" se caracterizaria por um entendimento de que os partidos competem entre si a partir de posicionamentos explícitos e contrários em diversos temas, portanto, afastando-se do centro do espectro político. Assim, "party policy differences on individual issues are separated from and independent of relative emphases on them and must be measured from direct statements of support or opposition to specific 
policy proposals” (Budge et al., 2001, 86). São poucos os trabalhos que se orientam a partir dessa abordagem unicamente, na maioria dos casos, ela é utilizada em conjunto com a abordagem da saliência em processo de codificação.

De certo modo, a maioria dos estudos sobre ideologia partidária a partir da análise de plataformas tende a se concentrar no primeiro enfoque. A quantidade de vezes que o texto expõe determinadas palavras passa a ser indicativo de determinado posicionamento e prioridades, no entanto, esse enfoque não se restringe à mera quantificação de palavras. A abordagem da saliência tomou forma, ao contrário dos estudos do CMP que se utilizavam não de computação ou frequência de palavras, mas de codificação manual. A codificação de sentenças em categorias amplas no estilo "a favor/ contra" se baseia no entendimento de que determinadas questões são próprias de certo partido, ainda que se possa perceber, também, um resquício da abordagem "confrontacionista” dos autores supracitados. A caracterização ideológica, segundo codificação do CMP, se baseia no entendimento de que, se o partido expressar a valorização da paz, portanto é a favor da paz, receberia um ponto que o atrelaria à esquerda do espectro político. Se, por outro lado, expressar o descontentamento com práticas de welfare, portanto é contra essas práticas, receberia uma pontuação que o colocaria na direita do espectro político. Ao fim, todas as sentenças (e quasi-sentences) estariam codificadas, e se faria uma conta simples: tantos pontos de direita menos tantos pontos de esquerda, e o resultado significaria seu posicionamento ideológico.

De fato, as abordagens e técnicas usadas na análise de documentos partidários mostram em ascendência, o que não impede que mesmo as mais recentes demonstram certas insuficiências. Em primeiro lugar, ao contrário do que postula os formuladores da "saliency theory", os partidos políticos nos Estados Unidos não parecem "converger" sobre posicionamentos políticos. Ao contrário do centro, os estudos mostram que há uma polarização partidária crescente. Longe de manter posicionamentos similares, os dois partidos que ali operam a nível nacional demonstram posicionamentos políticos antagônicos. Longe de se diferenciarem unicamente por prioridades distintas, se diferenciam por posicionamentos distintos. Por fim, longe de ser programas vagos e superficiais, preocupando-se com a repetição de determinados temas e palavras, as plataformas nos Estados Unidos 
são documentos extensos, complexos e bastante detalhados no que diz respeito à agenda política defendida.

Em segundo lugar, em relação ao difundido processo de codificação manual ou computacional, tal como o CMP, a formulação de categorias parece ser bastante questionável. Por exemplo, parte-se do pressuposto que a "direita" e a "esquerda" são as mesmas em todos os países e sistemas partidários, sendo que a "direita" valorizaria, segundo a codificação do CMP, conceitos como "liberdade" e "direitos humanos" enquanto a "esquerda" valorizaria a "paz" e a "democracia". Sem mais digressões, é muito frágil a afirmação de que a "direita" prioriza a "liberdade", como sendo esse o "seu" tema. De que "direita" estamos falando e de que tipo de "liberdade"? No caso do Partido Republicano, tipicamente caracterizado como um partido de "direita" nos Estados Unidos, a situação fica ainda mais crítica. No que se refere à plataforma de 2012, por exemplo, o partido é claramente a favor da liberdade econômica, ou seja liberdade para a iniciativa privada, e contra a liberdade no sentido de comportamento pessoal, o aborto e o casamento entre homossexuais, por exemplo. Como afirmar que "paz" e "democracia" são conceitos de "esquerda"? Talvez pela pretensão de se exportar determinadas ideologias partidárias para regiões tão distintas, se corre o risco de generalizar conceitos e ideologias que possuem diferentes aportes e definições dependendo de onde estão localizados. Por fim, como verificar a mudança ideológica de um mesmo partido baseando-se unicamente em uma dicotomia "a favor/contra"? E se o partido segue a favor de uma redução de programas de welfare em mais de uma plataforma, mas a gradação muda? Em função dos problemas expostos, este estudo propõe a fuga de termos maleáveis a partir de definições genéricas, como "direita e esquerda", bem como de tipificações simples a partir de categorias "a favor/contra".

Em terceiro lugar, na maior parte dos estudos já realizados, os programas partidários são analisados de maneira quantitativa (utilizando palavras, parágrafos e quasi-sentences como dados empíricos a ser quantificados e medidos em termos de frequência) e de maneira comparativa. Tendem, assim, a concentrar seus estudos na “embalagem" em que as plataformas estão envoltas, sua estrutura formal, palavras e temas mais frequentes, utilizando-se direta ou indiretamente da saliency theory. Mesmo a categorização e o posicionamento no espectro político direita vs. esquerda desenvolvido 
manualmente, ou por computação, têm base nessas características: utilizam-se da quantificação e da codificação de dados expostos na plataforma vis-à-vis ao programa de outro partido, conforme frequência e prioridade apresentadas. Ainda que esse tipo de técnica seja um pilar importante do estudo de programas partidários, não deveria ser a única. Por vezes, uma única frase, imersa em outras tantas, é capaz de produzir uma melhor caracterização ideológica de um partido do que o número de vezes que a palavra " $x$ " ou " $y$ " foi empregada.

A "embalagem" na qual uma plataforma partidária vem envolta merece, sim, atenção e pode ser um bom indicador de caracterização ideológica e mesmo de posicionamento no espectro político; no entanto, deveria ser tratada em conjunto com a "substância" da plataforma, ou seja, o conteúdo efetivo que dá origem a ela e que só pode ser compreendido a partir de uma análise qualitativa que leve em conta posições e princípios ideológicos apresentados. Este estudo ao buscar analisar uma suposta mudança ideológica intrapartidária está inserido em uma abordagem que privilegia tanto as ênfases e prioridades exaltadas pelas plataformas analisadas (a forma), como os posicionamentos e princípios ideológicos apresentados no "conteúdo" dessas mesmas plataformas (a substância). Se, de fato, houve uma "guinada conservadora" do Partido Republicano, essa mudança deve estar presente em suas plataformas nacionais, verificada tanto nas ênfases e prioridades, dadas pelo partido, como na linguagem usada e nos posicionamentos tomados diante de diferentes questões.

\section{Análise das plataformas republicanas de 1960 e 2012}

Antes de fazer uma análise da mudança ideológica do Partido Republicano, é importante caracterizar o que se entende por conservadorismo, já que esse conceito de no contexto norte-americano não é fixo, muda de acordo com conjunturas e proponentes, e apresenta desde a segunda metade do século XX (quando o conceito começa a ser mais amplamente difundido na academia e na política norte-americana) certas continuidades conceituais, podendo ser caracterizado da seguinte maneira ${ }^{8}$ a) rejeição a governos de amplo escopo na

8. Sobre o conservadorismo norte-americano, ver: Kirk (1953), Rossiter (1962), Nash (1996), Schneider (2009) entre outros. 
economia: seu papel deve ser de providenciar serviços essenciais e deixar que o livre mercado opere por si mesmo (portanto, rejeição a políticas de bem-estar social ou de redistribuição, por exemplo); b) defesa da moralidade e da religião cristã, bem como da família, tradições e valores norte-americanos (nesse sentido, é permitido um maior escopo de atuação do governo federal, ao contrário da economia); c) respeito à hierarquia e rejeição a qualquer tipo de nivelamento social ou econômico de maneira "artificial" (sendo a desigualdade a força motriz da sociedade); d) valorização da nação e do território, bem como da sua história, tradições e símbolos (bandeira, Constituição etc.); e) defesa ativa do território nacional e valorização das forças armadas; e f) exportação dos interesses nacionais de maneira ativa e relativamente autônoma (privilegia-se o unilateralismo em relação ao multilateralismo). Assim, o conservadorismo norte-americano pode ser definido em função de um caráter moralista e religioso, além de libertário na área econômica e militarista na política externa (ainda que esses conceitos não possuam, no seu cerne, um alto grau de associação entre si). Se, de fato, o Partido Republicano hoje é mais conservador, essas características deveriam estar presentes na sua plataforma.

\section{Estrutura, ênfases e linguagem}

Em relação à forma nas quais as duas plataformas se apresentam, é importante mencionar certas diferenças. Em primeiro lugar, o tamanho, a plataforma de 2012 apresenta um tamanho bastante superior a de 1960, o que indica uma maior variedade e aprofundamento de tópicos. Em segundo lugar, a complexidade de temas, em 1960 a plataforma lida com assuntos típicos abordados em uma candidatura, economia, agricultura, política externa etc. Já em 2012 a variedade e complexidade dos temas faz que se dê espaço a assuntos tão amplos que vão desde cyberterrorismo ao aquecimento global. Por fim, é importante lembrar que as plataformas refletem o momento em que foram escritas, portanto, refletem a conjuntura nacional e internacional naquele momento: Movimento Civil Rights e Guerra Fria em 1960 vs. crise econômica e terrorismo em 2012, por exemplo. Assim, as ênfases e a própria estrutura da plataforma não pode ser lida de maneira desassociada à realidade em que foi escrita. O importante é perceber, ali, as ênfases, linguagens e 
princípios conservadores - possíveis de ser verificados mesmo em diferentes contextos.

Tabela I - Estrutura das plataformas republicanas de 1960 e 2012

\begin{tabular}{|c|c|c|}
\hline & 1960 & 2012 \\
\hline Total de páginas & 26 ( $10.68 \mathrm{I}$ palavras $)$ & 59 (30.564 palavras) \\
\hline Tópicos abordados & 23 & 7 (98 subtópicos) \\
\hline $\begin{array}{l}\text { Porcentagem destinada à } \\
\text { política econômica9 }\end{array}$ & I0,3\% (I.I0I palavras) & $17,7 \%$ (5.422 palavras) \\
\hline $\begin{array}{l}\text { Porcentagem destinada a } \\
\text { políticas e questões sociais }{ }^{10}\end{array}$ & 37\% (3.952 palavras) & $32,1 \%$ (9.8I7 palavras) \\
\hline $\begin{array}{l}\text { Porcentagem destinada à } \\
\text { política externa e de defesa" }\end{array}$ & $22,8 \%$ (2.442 palavras) & $25,8 \%$ (7.878 palavras) \\
\hline $\begin{array}{l}\text { Porcentagem destinada a } \\
\text { outros temas }{ }^{12}\end{array}$ & $29,8 \%$ (3.186 palavras) & $24,3 \%$ (7.447 palavras) \\
\hline
\end{tabular}

Fonte: Elaboração da autora.

9. Tais como: política fiscal, monetária e alfandegária; bem como finanças e administração do Estado, inflação entre outras. Tópicos e subtópicos inclusos nessa categoria: Plataforma de 1960: Economic Growth and Business e Government Administration. Plataforma de 2012: Restoring the American Dream: Rebuilding the Economy and Creating Jobs (tópico completo); Living within our means;

10. Estão incluídas nessas categorias as políticas de bem-estar social - saúde pública, aposentadoria, ocupação (labor), justiça, moradia (housing) etc.; bem como aquelas que dizem respeito ao comportamento humano - aborto, divórcio, casamento, drogas etc. Também chamada de "políticas sociais" nos Estados Unidos (social policies), optou-se por chamar estas últimas de "questões sociais" para diferenciá-las da primeira. Tópicos e subtópicos parte dessa categoria: Plataforma de 1960: Labor, Education, Human Needs, Older Citizens, Health Aid, Juvenile Delinquency, Veterans, Indian Affairs, Housing, Health, Protection of Consumers, Civil Rights e Immigration. Plataforma de 2012: Renewing American Values to Build Healthy Families (tópico completo); Defending marriage against an activist judiciary; A sacred contract; The first amendment; The second Amendment; The fourth amendment; The fifth amendment; The ninth amendment; The sanctity of human life; Saving Medicare for future generations; Strengthening Medicaid in the States; Security for those who need it; The rule of Law; Honoring our relationship with American Indians e Modernizing the Federal civil services (subtópicos).

11. Tópicos que fazem parte dessa categoria: Plataforma de 1960: Foreign Policy e National Defense. Plataforma de 2012: American Excepcionalism.

12. Dentre eles, temas como meio ambiente, internet, esferas de governo etc. 
Tabela 2 - Palavras mais citadas nas plataformas republicanas de 1960 e $2012^{13}$

\begin{tabular}{cc}
1960 & 2012 \\
\hline Program(s) (69x) & Government (I24x) \\
Federal (67x) & American(s) (II7x) \\
Government (47x) & Federal (II5x) \\
New (43x) & Support (93) \\
Nation(s) (17+24x, respectivamente) & States (89) \\
Support (40x) & Current (85x) \\
National (36x) & Administration (75x) \\
Republican (33x) & People (73x) \\
Free (3Ix) Obs: Freedom (23x) & America (69x) \\
World (30x) & Public (62x) \\
\hline
\end{tabular}

Fonte: Elaboração da autora.

Em relação à Tabela 1, ainda que se verifique uma valorização um pouco maior da economia na plataforma de 2012 (talvez pela conjuntura interna de crise econômica), os outros âmbitos são relativamente similares. Nos dois casos houve certa convergência de espaço relativo a cada temática supracitada. Da mesma maneira, verifica-se certa semelhança no que diz respeito às palavras frequentemente mais usadas nas plataformas. Termos típicos, como "governo" e "federal", por exemplo, figuram entre os dez mais citados em ambos os programas. No entanto, ao desconsiderar essas palavras previsíveis, verifica-se uma leve diferença na amplitude e no escopo de prioridades de ambos os programas. Em 1960, por exemplo, palavras como "free", "freedom" e "world" ganham prioridades que não se repetem em 2012, ao buscar enfatizar palavras como "American(s)", "America”, "states", "people" entre outras; e que poderiam indicar ênfases distintas (externo vs. interno, por exemplo $)^{14}$. Essa dedução é bastante frágil de se manter por se referir a conjunturas diferentes: Guerra Fria vs. crise econômica nacional. De fato, uma análise mais apurada das plataformas, concentrando-se nas áreas temáticas supracitadas, nos revela mudanças mais visíveis, em especial no que tange à política externa.

13. Software utilizado: ManyEyes.

14. Em especial se levarmos em conta o fato de que palavras como "people", "states" e “public" se referem, na plataforma de 2012, ao contexto doméstico - perceptível a partir de uma análise de redes de palavra (Many Eyes). 
Tabela 3 - Palavras mais citadas nas plataformas republicanas (I960 e 20I2) de acordo com o tema ${ }^{15}$

\begin{tabular}{lcc} 
& 1960 & 2012 \\
\hline $\begin{array}{l}\text { Política } \\
\text { econômica }\end{array}$ & Economic/Economy (I8x), & Tax(es) (4Ix), American(s) (36x), \\
& Government (9x), Federal & Economic/Economy (35x), Federal \\
& $(8 x)$, National (8x), Growth & $(26 x)$, Government (24x) \\
Políticas e & Federal (38x), Program(s) & Federal (5Ix), Americans (49x), \\
questões & $(29 x)$, School(s) (24x), Educa- & Support (43x), Government(s) (42x), \\
sociais & tion (22x), Government (17x) & Public (34x) \\
Política & Nations (19x), World (19), & Military (43x), National (30x), Secu- \\
externa e de & Freedom (16x), United (I2), & rity (29x), President (27x), Adminis- \\
defesa & Peace (10), Security (10) & tration (27x), America (25x) \\
\hline
\end{tabular}

Fonte: Elaboração da autora.

A partir da análise dos dados supracitados, podemos inferir duas proposições: verifica-se uma maior valorização da nação e dos nacionais em 2012 em relação a 1960; e com exceção da política externa e de defesa (em que se nota uma clara mudança: ênfase na liberdade, paz e segurança do mundo e das nações em 1960, em contraposição a uma maior ênfase na segurança, nas forças armadas e no nacional em 2012); as outras duas temáticas não são representativas de mudança ideológica (ao menos com esse reduzido número de palavras). De fato, é difícil verificar mudanças utilizando apenas palavras como dados na economia, por exemplo, em que há a recorrência de termos retóricos e típicos dessa área. Como verificar o caráter mais conservador nessa área no que diz respeito a impostos? A frequência de palavras não nos indica variações de grau ou de escopo, se gradativo e redistributivo, por exemplo, o que limita uma compreensão do fenômeno de maneira mais assertiva.

A análise de conteúdo a partir do uso de palavras, no entanto, pode ser um bom indicador se buscamos correlações e comparações a partir da presença ou ausência de palavras-chave. Ou seja, se entendemos que o conservadorismo enfatiza a moralidade, a religião, a valorização da nação, das tradições (símbolos, Constituição, história etc.), da família, da defesa da nação através de forças armadas, por exemplo, podemos verificar a presença de determinadas palavras nas plataformas e que

15. Software utilizado: ManyEyes. 
poderiam servir de indicativo de uma maior ou menor presença do conservadorismo. E, de fato, o que uma análise dessa natureza nos mostra corrobora para a hipótese de acirramento conservador por parte do Partido Republicano, como se pode perceber a seguir.

Tabela 4 - Ênfase na religião (número de palavras citadas) ${ }^{16}$

\begin{tabular}{lcc} 
& $\mathbf{1 9 6 0}$ & $\mathbf{2 0 I 2}$ \\
\hline Faith (ful, fully) & 5 & 23 \\
God & 1 & 10 \\
Sacred & 0 & 4 \\
Religious (ly) e Religion & 4 & 40 \\
Providence (divine) & 0 & 2 \\
Total & 10 & 79 \\
Porcentagem na plataforma & $0,09 \%$ & $0,25 \%$ \\
\hline
\end{tabular}

Fonte: Elaboração da autora.

Tabela 5 - Ênfase na família, nos valores e na moralidade (número de palavras citadas)

\begin{tabular}{lcc} 
& 1960 & $\mathbf{2 0 I 2}$ \\
\hline Family (ies) & 8 & 56 \\
Marriage (ied, ying) & 0 & 23 \\
Community (ies) & 10 & 31 \\
Values & 0 & 16 \\
Moral (ity) & 1 & 8 \\
Total: & 19 & 134 \\
Porcentagem na plataforma & $0,17 \%$ & $0,43 \%$ \\
\hline
\end{tabular}

Fonte: Elaboração da autora.

Tabela 6 -Valorização da nação, da tradição e da Constituição (número de palavras citadas)

\begin{tabular}{lcc}
\hline & 1960 & $\mathbf{2 0 I 2}$ \\
\hline Nation (al, ality, ally) & 54 & 129 \\
America & 11 & 69 \\
American(s) & 25 & 161 \\
United States & 12 & 31 \\
Constitution (s, al, ally, alist, constituents) & 6 & 56 \\
Tradition (s, al, ally) & 3 & 19 \\
Total & 111 & 465 \\
Porcentagem na plataforma & $1 \%$ & $1,5 \%$ \\
\hline
\end{tabular}

Fonte: Elaboração da autora. 
Se, ao contrário, buscamos verificar princípios não característicos do conservadorismo como "igualdade", por exemplo, (afinal, o conservadorismo se define justamente por defender a desigualdade como força motriz do progresso e reflexo de uma "obra divina" ${ }^{17}$ ), tipicamente associado à ótica liberal (tal como no contexto norte-americano); verificamos uma inversão de ênfases, agora privilegiando a plataforma de 1960.

Tabela 7 - Ênfase na "igualdade" (número de palavras citadas)

\begin{tabular}{lcc}
\hline & 1960 & 2012 \\
\hline Equal (ity, ly) & 19 & 10 \\
Porcentagem na plataforma & $0,17 \%$ & $0,03 \%$ \\
\hline
\end{tabular}

Fonte: Elaboração da autora.

Por fim, ao analisar a "forma” das plataformas, é possível verificar certas mudanças. Em primeiro lugar, há uma maior valorização da nação e dos nacionais, como se a ênfase agora fosse mais interna e autônoma em relação ao período anterior (Tabela 2). Em segundo lugar, a área de política externa demonstra (Tabela 3) uma inversão de prioridades: enquanto em 1960 são priorizadas palavras como "paz”, "liberdade", "segurança”, "mundo" e "nações” (e não "a” nação); em 2012 privilegia-se "a nação", bem como as "forças armadas”. Essa mudança não reflete meramente conjunturas distintas, afinal enquanto a primeira está imersa nas tensões e no conflito da Guerra Fria, portanto um momento cuja ênfase nas forças armadas e na defesa interna seria bastante cabível; a segunda faz parte de um contexto de relativa paz mundial. Enfatizar conceitos como "América" e "forças armadas" é refletir mais que a conjuntura do momento, é colocar em foco as próprias prioridades do partido: valorização da nação e da defesa através das forças armadas - princípios propriamente conservadores. Por fim, a maior escolha de palavras com viés religioso e aquelas relativas à família, valores, nação e tradição mostra-se, novamente, estar em acordo com os princípios conservadores de valorização da moralidade, da religião, das tradições, bem como da família e da nação. A análise da "forma" da plataforma, nesse sentido, parece proporcionar bons indicadores de mudança ideológica por parte do Partido Republicano e corrobora a hipótese deste trabalho.

17. Kirk (1953). 


\section{Posicionamentos}

Uma análise centrada unicamente na "forma" da plataforma, ainda que importante no que diz respeito à verificação de diferentes ênfases e linguagens, não é capaz de mostrar determinadas questões mais factuais. Por exemplo, pouco ou nada se pode inferir a respeito da condução de políticas econômicas. Da mesma forma é difícil verificar uma proposta de atuação real do partido referente à moralidade. $\mathrm{O}$ maior uso de palavras que denotam componentes religiosos e morais, nesse sentido, demonstra uma mudança importante de linguagem, mas não necessariamente de posicionamento. Assim, busca-se, nesta última parte deste trabalho, comparar determinadas instâncias que nos indicam, de maneira mais assertiva, a suposta "radicalização" conservadora por parte do Partido Republicano.

Quadro I - Posicionamentos nas plataformas republicanas de 1960 e 2012

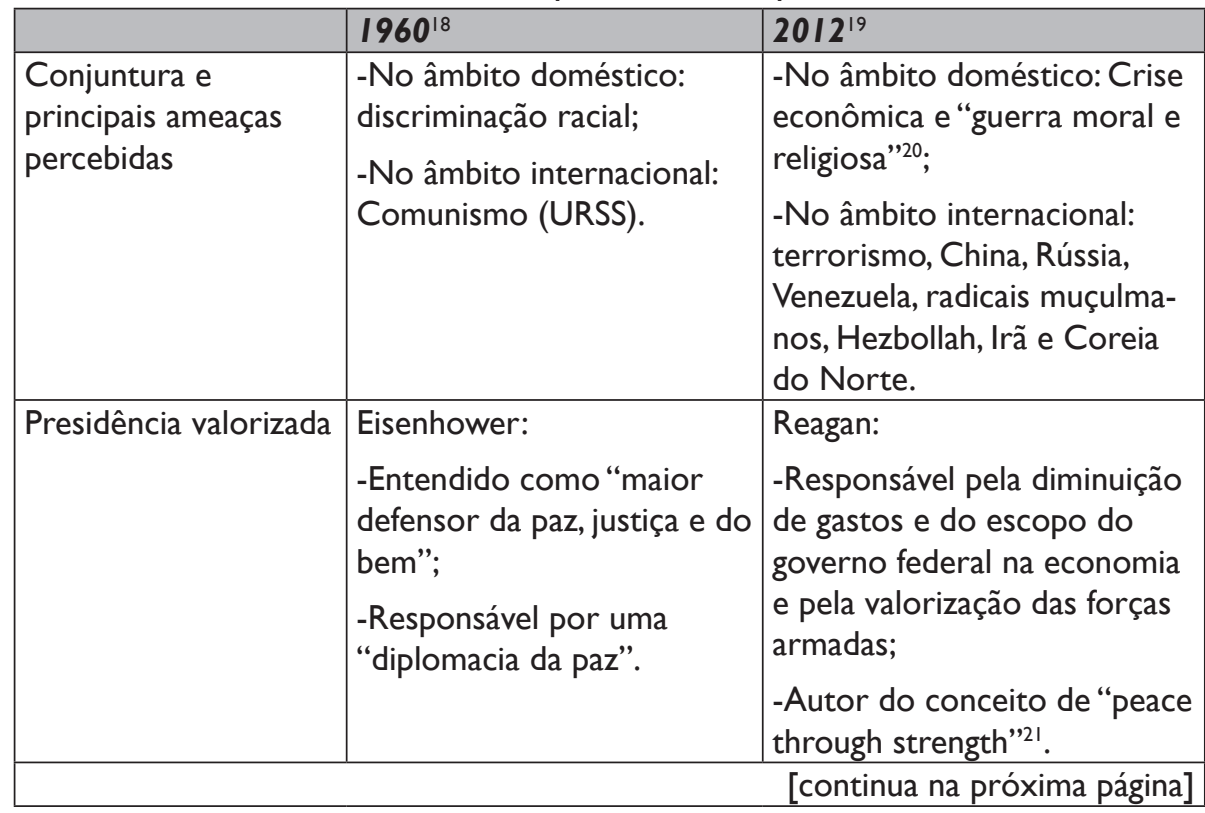

18. Todas as citações: Republican Party, 1960.

19. Todas as citações: Republican Party, 2012.

20. Entendida como políticas públicas, legislação e ideais que corrompem a família, a moralidade, a religião e os valores tradicionais Entendida como políticas públicas, legislação e ideais que corrompem a família, a moralidade, a religião e os valores tradicionais

21. Paz mundial por meio de crescimento econômico e fortalecimento das forças armadas norte-americanas. 


\begin{tabular}{|c|c|c|}
\hline & 1960 & 2012 \\
\hline $\begin{array}{l}\text { Papel do governo } \\
\text { federal }\end{array}$ & $\begin{array}{l}\text {-Desempenha papel positi- } \\
\text { vo na economia: é árbitro } \\
\text { entre mercado e sociedade; } \\
\text { e condiciona o crescimento } \\
\text { econômico; } \\
\text {-Promoção de políticas } \\
\text { públicas e de "ambiente" } \\
\text { que contribua para o fim da } \\
\text { descriminação; } \\
\text {-Defesa da nação através de } \\
\text { negociações internacionais. }\end{array}$ & $\begin{array}{l}\text {-Desempenha papel negativo } \\
\text { na economia: deve restringir- } \\
\text {-se à promoção de serviços } \\
\text { essenciais previstos na Cons- } \\
\text { tituição; } \\
\text {-Recuperação dos valores e } \\
\text { tradições norte-americanos, e } \\
\text { promoção da moralidade, da } \\
\text { religião e do fortalecimento } \\
\text { da família através de progra- } \\
\text { mas e incentivos; } \\
\text {-Defesa da nação através do } \\
\text { fortalecimento das forças } \\
\text { armadas. }\end{array}$ \\
\hline $\begin{array}{l}\text { Economia - sistema } \\
\text { de impostos }\end{array}$ & $\begin{array}{l}\text {-Deve ser "justo, equitativo } \\
\text { e aprovado pela sociedade". }\end{array}$ & $\begin{array}{l}\text {-Deve ser mínimo, simples e } \\
\text { universal. }\end{array}$ \\
\hline $\begin{array}{l}\text { Rede de proteção } \\
\text { e bem-estar social } \\
\text { (welfare) }\end{array}$ & $\begin{array}{l}\text {-Valorização de programas } \\
\text { e serviços federais (saúde, } \\
\text { aposentadoria, transportes, } \\
\text { serviço postal etc.) através } \\
\text { de expansão e maiores } \\
\text { incentivos; } \\
\text {-Aumento do salário míni- } \\
\text { mo e extensão do seguro- } \\
\text {-desemprego; } \\
\text {-Maiores compensações aos } \\
\text { empregados federais; } \\
\text {-Incentivos a escolas e } \\
\text { universidades na área de } \\
\text { pesquisa; }\end{array}$ & $\begin{array}{l}\text { - Programas federais devem } \\
\text { ser enxugados e colocados } \\
\text { em competição com a iniciati- } \\
\text { va privada (saúde e aposenta- } \\
\text { doria, por exemplo); } \\
\text { - Deixar a cargo da iniciativa } \\
\text { privada: setor ferroviário e } \\
\text { serviço postal; } \\
\text { - Redução da folha salarial } \\
\text { federal; }\end{array}$ \\
\hline $\begin{array}{l}\text { Rede de proteção } \\
\text { e bem-estar social } \\
\text { (welfare) }\end{array}$ & $\begin{array}{l}\text {-Extensão de empréstimos } \\
\text { federais para estudantes e } \\
\text { diminuição de taxas para } \\
\text { custear estudos. }\end{array}$ & $\begin{array}{l}\text {-Regulações na saúde pública } \\
\text { que visem uma maior res- } \\
\text { ponsabilidade pessoal; e na } \\
\text { aposentadoria referente a um } \\
\text { novo marco etário; } \\
\text {-Diminuição do crédito } \\
\text { federal para estudantes e para } \\
\text { custeio de estudos. }\end{array}$ \\
\hline
\end{tabular}




\begin{tabular}{|c|c|c|}
\hline & 1960 & 2012 \\
\hline $\begin{array}{l}\text { Nivelamento social } \\
\text { ou econômico }\end{array}$ & $\begin{array}{l}\text {-Valorização de políticas } \\
\text { igualitárias em um sentido } \\
\text { amplo: oportunidades, edu- } \\
\text { cação, direitos, tratamento } \\
\text { etc.; } \\
\text {-A favor de um papel mais } \\
\text { ativo da Suprema Corte } \\
\text { que formalize a igualdade } \\
\text { racial. }\end{array}$ & $\begin{array}{l}\text {-Contra sistema de impostos } \\
\text { retroativos, responsáveis por } \\
\text { "dividir americanos e promo- } \\
\text { ver luta de classes”; } \\
\text {-Contra atuação do governo } \\
\text { ou da Suprema Corte no } \\
\text { estabelecimento de políticas } \\
\text { de nivelamento econômico: } \\
\text { "Mérito, habilidade, aptidão } \\
\text { e resultados devem ser os } \\
\text { fatores que determinam o } \\
\text { progresso na sociedade”; } \\
\text {-Contra o papel ativo da } \\
\text { Suprema Corte no que diz } \\
\text { respeito à legalização do } \\
\text { aborto e ao casamento entre } \\
\text { homossexuais; } \\
\text {-lgualdade entendida como } \\
\text { aquela perante a lei (de } \\
\text { acordo com a Constituição) e } \\
\text { perante Deus. }\end{array}$ \\
\hline $\begin{array}{l}\text { Moralidade e religião } \\
\text { (cristã) }\end{array}$ & $\begin{array}{l}\text {-Não faz menção à religião; } \\
\text {-A única menção à morali- } \\
\text { dade diz respeito à discri- } \\
\text { minação racial, entendida } \\
\text { como “imoral” e “injusta”. }\end{array}$ & $\begin{array}{l}\text {-Moralidade e religião como } \\
\text { ferramentas indispensáveis } \\
\text { para a democracia e para } \\
\text { o bom funcionamento da } \\
\text { sociedade; } \\
\text {-Trazer a religião e a mora- } \\
\text { lidade para dentro da esfera } \\
\text { política e fomentá-las na } \\
\text { sociedade; }\end{array}$ \\
\hline
\end{tabular}




\begin{tabular}{|c|c|c|}
\hline & 1960 & 2012 \\
\hline $\begin{array}{l}\text { Moralidade e religião } \\
\text { (cristã) }\end{array}$ & & $\begin{array}{l}\text {-Fortalecimento das insti- } \\
\text { tuições religiosas através de } \\
\text { incentivos fiscais e ampliação } \\
\text { na área de atuação; } \\
\text {-É considerado imoral: discri- } \\
\text { minação, aborto, casamento } \\
\text { homossexual e políticas públi- } \\
\text { cas que visam desestruturar a } \\
\text { família e a religião; } \\
\text { - Valorização e extensão de } \\
\text { atividades das instituições } \\
\text { religiosas (diplomacia, ajuda } \\
\text { humanitária, papel na educa- } \\
\text { ção etc.); } \\
\text {-Trazer a religião para a } \\
\text { esfera pública: defesa da li- } \\
\text { berdade de praticar preceitos } \\
\text { religiosos em locais públicos; } \\
\text { e exposição de símbolos reli- } \\
\text { giosos em locais e instituições } \\
\text { públicas. }\end{array}$ \\
\hline $\begin{array}{l}\text { Família, valores e } \\
\text { tradição norte-ame- } \\
\text { ricanos }\end{array}$ & -Não faz menção. & $\begin{array}{l}\text { - Família entendia como } \\
\text { "instituição fundamental da } \\
\text { nação": responsável pela } \\
\text { manutenção e reprodução de } \\
\text { valores e tradições; } \\
\text {-Valorização da família e do } \\
\text { casamento (entre homem e } \\
\text { mulher), entendido como um } \\
\text { "contrato sagrado", através } \\
\text { da defesa do DOMA (Defen- } \\
\text { se of the Marriage Act); } \\
\text {-Valorização do papel dos } \\
\text { pais na educação e formação } \\
\text { da cidadania. }\end{array}$ \\
\hline $\begin{array}{l}\text { Nação, história e } \\
\text { símbolos norte-ame- } \\
\text { ricanos }\end{array}$ & -Não faz menção. & $\begin{array}{l}\text { - Defesa de uma legislação } \\
\text { que: obrigue estabelecimen- } \\
\text { tos públicos exibir a bandeira } \\
\text { dos Estados Unidos; promova } \\
\text { o canto do hino nacional nas } \\
\text { escolas e atividades públicas; }\end{array}$ \\
\hline & & [continua na próxima página] \\
\hline
\end{tabular}




\begin{tabular}{|c|c|c|}
\hline & 1960 & 2012 \\
\hline $\begin{array}{l}\text { Nação, história e } \\
\text { símbolos norte-ame- } \\
\text { ricanos }\end{array}$ & & $\begin{array}{l}\text {-Valorização da Constituição } \\
\text { e dos ideais por ela expostos } \\
\text { através de uma "restauração } \\
\text { do governo constitucional" } 22 \text {. }\end{array}$ \\
\hline $\begin{array}{l}\text { Defesa, território } \\
\text { nacional e forças } \\
\text { armadas }\end{array}$ & $\begin{array}{l}\text {-Defesa é projeto em con- } \\
\text { junto através de concerta- } \\
\text { ção, alianças, programas e } \\
\text { organismos multilaterais; } \\
\text {-Ênfase na “diplomacia da } \\
\text { paz”: diálogos estratégicos } \\
\text { para redução de conflitos; } \\
\text {-Manutenção das forças ar- } \\
\text { madas (nem aumento, nem } \\
\text { corte de gastos), mas ênfase } \\
\text { na diplomacia. }\end{array}$ & $\begin{array}{l}\text {-Defesa é projeto "solo" } \\
\text { através de uma economia e } \\
\text { capacidade militar robustas } \\
\text { (melhor economia e forças } \\
\text { armadas do mundo); } \\
\text {-Aumento nos gastos com as } \\
\text { forças armadas e fortaleci- } \\
\text { mento do setor militar; } \\
\text {-Defesa de um "arsenal es- } \\
\text { tratégico, forte e efetivo para } \\
\text { detenção de competidores". }\end{array}$ \\
\hline $\begin{array}{l}\text { Unilateralismo e mul- } \\
\text { tilateralismo }\end{array}$ & $\begin{array}{l}\text { Multilateralismo: } \\
\text {-A condução da política } \\
\text { externa é dependente da } \\
\text { concertação de compromis- } \\
\text { sos e arranjos multilaterais; } \\
\text {-Fortalecimento dos antigos } \\
\text { e promoção de novos pro- } \\
\text { gramas e arranjos institu- } \\
\text { cionais multilaterais; } \\
\text {-Manutenção dos compro- } \\
\text { missos firmados no âmbito } \\
\text { internacional; } \\
\text {-Ajuda financeira e assistên- } \\
\text { cia militar aos aliados. }\end{array}$ & $\begin{array}{l}\text { Unilateralismo: } \\
\text {-A condução da política } \\
\text { externa independe de com- } \\
\text { promissos ou de arranjos } \\
\text { multilaterais; } \\
\text { - Pragmatismo e soberania na } \\
\text { atuação em organismos multi- } \\
\text { laterais - busca por liderança } \\
\text { nesses organismos; } \\
\text { - Rejeição de compromissos } \\
\text { firmados ou a firmar que } \\
\text { possam impactar na família, } \\
\text { economia ou mesmo na } \\
\text { soberania norte-americana } \\
\text { (considerados contrários à } \\
\text { Constituição); } \\
\text {-Ajuda externa não é papel } \\
\text { do governo, deve ser feita } \\
\text { de maneira voluntária pelos } \\
\text { "faith based groups". }\end{array}$ \\
\hline
\end{tabular}

Fonte: Elaboração da autora.

22. Ao contrário de 1960, a plataforma de 2012 expõe um tópico que versa sobre a importância da Constituição: "We, the people: A restoration of Constitutional Governemnt”. 
Em uma leitura mais aprofundada das duas plataformas republicanas nos mostra certas semelhanças: em ambos os casos professa-se a defesa de um escopo de governo menor na economia e de responsabilidade na condução de gastos públicos, por exemplo; no entanto, são as diferenças no que diz respeito a princípios conservadores, que são mais enfatizados e mais visíveis nas plataformas.

Primeiramente, no que tange ao papel e escopo do governo federal, é possível perceber uma distinção entre ambas as plataformas. Em 1960, o governo é visto de maneira a balizar as forças do livre mercado e corrigir aspectos negativos deste, buscando se estabelecer como árbitro das relações sociedade $v$ s. livre mercado. O governo, nesse sentido, possui uma atuação mais abrangente no setor econômico, em especial na rede de proteção social. Essa, por sua vez, pode ser percebida desde uma relativa valorização de programas federais à ingerência em assuntos como salário-mínimo, benefícios a servidores públicos e veteranos de guerra. Por outro lado, não se nota a defesa de um papel amplo do governo federal em questões sociais de comportamento no apelo à moralidade, na ênfase na religião ou na condução da sociedade a partir de determinados valores e normas tradicionais. Além disso, no que tange ao exterior, se verifica a constante ênfase na paz através da diplomacia, diálogos estratégicos e concertação por meio de parcerias e instituições multilaterais. Assim, nota-se um componente "liberal" na plataforma defendida em 1960 pelo Partido Republicano: preocupação com uma rede de bem-estar social e condução da economia de maneira a restringir os efeitos desiguais do livre mercado; distanciamento do governo no que diz respeito a normas de condução da sociedade; e ênfase dos organismos e instituições multilaterais na condução da política externa. Esse componente "liberal", no entanto, vai estar praticamente ausente em 2012.

De fato, se entendemos por conservadorismo os princípios já identificados, a plataforma mais recente do Partido Republicano poderia ser entendida como uma "receita" conservadora: defesa da ideia de governo mínimo na economia e, portanto, uma valorização do livre mercado e da iniciativa privada; defesa de uma redução do escopo e do papel do governo em programas e iniciativas federais associadas à rede de proteção e de bem-estar social; valorização do papel da religião e da moralidade na condução da sociedade e também da política; defesa do papel da família tradicional na condução 
da sociedade; valorização da história, das tradições e dos símbolos nacionais - inclusive a Constituição; e valorização do território, das forças armadas e de uma política externa que busca a soberania e a autonomia nas relações internacionais.

\section{Considerações finais}

Buscou-se neste trabalho analisar a suposta radicalização conservadora do Partido Republicano por meio de uma abordagem que privilegia o uso de programas partidários. Utilizando-se de uma metodologia baseada tanto em ferramentas informacionais como na interpretação e categorização dos programas, verificou-se uma mudança ideológica de amplo escopo, desde a forma das plataformas analisadas, com suas diferentes linguagens e ênfases, ao conteúdo nelas explicitado. Esta análise corrobora a hipótese bastante difundida na literatura norte-americana a respeito de uma mudança ideológica republicana. No entanto, é bastante preliminar e demonstra a necessidade de maiores estudos tanto sobre o tema quanto acerca da metodologia empregada. Ainda que seja uma abordagem sucinta, é possível verificar o potencial de estudos que fazem uso das plataformas de partidos políticos como um instrumento nos estudos de ideologia partidária.

\section{Referências}

BLACK, E.; BLACK, M. (2007). Divided America. New York: Simon \& Schuster.

BREWER, M. D.; STONECASH, J. M. (2009). Dynamics of american political parties. New York: Cambridge University.

BUDGE, I.; KLINGEMANN, H.-D.; VOLKENS, A.; BARA, J.; TANENBAUM, E. (2001). Mapping policy preferences: estimates for parties, electors, and governments 1945-1998. New York: Oxford University.

BUDGE, I.; ROBERTSON, D.; HEARL, D. (eds.). (1987). Ideology, strategy and party change: spatial analysis of post-war election programmes in 19 democracies. Cambridge: Cambridge University.

CMP-MPG. Manifest Project Database. Disponível em: [https://manifesto-project. wzb.eu/]. Acesso em 3 dezembro 2013.

FIORINA, M. P. (1999). What happened to the medium voter? MIT CONFERENCE ON PARTIES AND CONGRESS. Disponível em: [http://www.stanford.edu/ mfiorina/Fiorina\%20Web\%20Files/MedianVoterPaper.pdf]. Acesso em 12 de janeiro de 2013. 
. (2005). Culture war? The myth of a polarized America. New York: Pierson Longman.

FIORINA, M. P.; ABRAMS, S. J. (2008). Political polarization in the american public. Annual Review of Political Science, vol. 11, p. 563-88. Disponível em: [http:// www.acsu.buffalo.edu/ jcampbel/documents/AnnualReviewFiorina.pdf]. Acesso em 4 de agosto de 2012.

FISHEL, J. (1985). Presidents and promises. Washington: Congressional Quarterly.

GINSBERG, B. (1976). Elections and public policy. The American Political Science Review, vol. 70, n. 1, p. 41-9, mar.

KIRK, R. (1953). The conservative mind: from Burke to Santayana. Chicago: Henry Regnery Company.

JACOBSON, G. (2005). Polarized politics and the 2004. Congressional and Presidential Elections. Political Science Quartelry, vol. 120, n. 2, p. 199-218.

LASSWELL, H. D.; NAMENWIRTH, J. Z. (1970). The changing language of american values: a computer study of selected party platforms. Comparative Politics Series - Series n. 01-001. vol. 1. Beverly Hills: SAGE.

LAVER, M. (2001). Estimating the policy positions of political actors. London: Routledge.

LAVER, M. J.; BUDGE, I. (eds.). (1992). Party policy and government coalitions. New York: St. Martin's.

LAVER, M.; BENOIT, K.; GARRY, J. (2003). Extracting policy positions from political texts using words as data. The American Political Science Review, vol. 97, n. 2, p. 311-31, maio.

LAVER, M.; GARRY, J. (2000). Estimating policy positions from political texts. American Journal of Political Science, vol. 44, n. 3, p. 619-34, jul.

LAYMAN, G. (2001). The great divide: religious and cultural conflicts in american party politics. New York: Columbia University.

LEVENDUSKY, M. (2009). The partisan sort. Chicago: The University of Chicago.

MAISEL, S. (1993-1994). The platform written process: candidate-centered platforms in 1992. Political Science Quarterly, vol. 108, n. 4, p. 671-98.

MANN, T. E.; ORNSTEIN, N. J. (2012). It's even worse than it looks. New York: Basic Books.

McCARTY, N.; POOLE, K. T.; ROSENTHAL, H. (2006). Polarized America. London: The MIT.

MONROE, A. (1983). American party platforms and public opinion. American Journal of Political Science, vol. 27, n. 1, p. 27-42, fev.

NASH, G. H. (1996). The conservative intellectual movement in America since 1945. Wilmington: Intercollegiate Studies Institute. 
PIERSON, P.; HACKER, J. (2005). Off center: the republican revolution and the erosion of american democracy. New Haven: Yale University.

POMPER, G. (1967). "If elected, I promise": American party platforms. Midwest Journal of Political Science, vol. 11, n. 3, p. 318-52, ago.

REPUBLICAN PARTY. (1960). Republican party national platform. Disponível em: [ http://www.presidency.ucsb.edu/]. Acesso em 20 de agosto de 2012. . (2012). Republican party national platform. Disponível em: [http://www. presidency.ucsb.edu/]. Acesso em 20 agosto 2012.

ROSSITER, C. (1962). Conservatism in America: the thankless persuation. New York: Vintage Books.

SCHNEIDER, G. L. (2009). The conservative century: from reaction to revolution. Lanham: Rowman and Littlefield Publishers.

SELIGER, M. (1976). Ideology and politics. Birkenhead: Wilmer Brothers.

SINCLAIR, B. (2006). Party wars. Oklahoma: Oklahoma University.

SLAPIN, J.; PROKSCH, S.-O. (2008). A scaling model for estimating time-series party positions from texts. American Journal of Political Science, vol. 52, n. 3, p. 705- 22, jul.

STONECASH, J. M. (ed.). (2010). New directions in american political parties. New York: Routledge.

WEINBERG, M. W. (1977-1978). Writing the republican platform. Political Science Quarterly, vol. 92, n. 4, p. 655-62, inver. 